\title{
Effect of chromium on germination in some crops of India.
}

\author{
Nitesh Joshi $^{1 *}$, Pallavi Menon', Ambika Joshi ${ }^{2}$ \\ ${ }^{1}$ Department of Botany, Rizvi College of Arts, Science and Commerce, Mumbai, India \\ ${ }^{2}$ Department of Botany, Jai Hind College, Mumbai, India
}

\begin{abstract}
Industrial development and scientific advancement has contaminated the environment, as a result one of the major pollutants in the environment are heavy metals and their introduction in air, water and agricultural soil. In recent years, chromium has become a major environmental pollutant as it widely used in making alloys, electroplating of stainless steel, production of pigments. Many studies have been carried out on heavy metals to understand their detrimental effects in the ecosystem. In the present study, Chromium was selected to find out its harmful effects on seed germination and seedling growth of Vigna radiata L, Trigonella foenum-graceum L, Oryza sativa L, Sorghum vulgare L and Pennisetum glaucum $\mathrm{L}$. Seeds of the selected plants were grown in petri dishes and treated with varying concentrations of Chromium solution. Each treatment was replicated in a randomised design and observed for $\mathbf{7}$ days. The developing seedlings were studied for their total rate of germination, seed vigour index, length of radicle, length of plumule and fresh weight compared to a set of seeds germinated using distilled water as control. It was observed that the harmful effects of chromium on all the parameters were directly proportional to the concentration of solution employed, with the inhibition of growth being pronounced from $50 \mathrm{ppm}$ onwards. Based on the response of the plants the toxic effect of chromium was seen in the following order, Trigonella foenum-graceum $\mathrm{L}>$ Oryza sativa $\mathrm{L}>$ Pennisetum glaucum $\mathrm{L}>$ Sorghum vulgare $\mathrm{L}>$ Vigna radiata $\mathrm{L}$.
\end{abstract}

Keywords: Chromium, Seed germination, Toxicity, Crop.

Accepted on January 28, 2019

\section{Introduction}

Heavy metals are substances naturally occurring in the Earth's crust; it is the significant rise in human activities that has caused soil contamination by heavy metals. Heavy metals are elements with a high density of $4 \mathrm{~g} / \mathrm{cm}^{3}$; some of these are required in trace amounts and vital for maintaining human health. Heavy metals disrupt the functioning of an organ by accumulating in the tissues thus displacing vital nutrients. Some heavy metals are essential for growth; however at higher levels it becomes toxic to living organisms. Chromium is one such nutrient required for sugar and fat metabolism in humans, whereas the role of chromium in plant growth and its uptake pathway are not yet fully understood. Plant uptake of Cr (III) is a passive process, that is, no energy expenditure is required by the plant $[1,2]$. The uptake of $\mathrm{Cr}$ (VI) is thought to be an active mechanism performed by carriers for the uptake of essential elements such as sulphate $[3,4]$. Other studies have reported that plants experience oxidative stress upon exposure to heavy metals that leads to cellular damage and disturbance of cellular ionic homeostasis, in fact disrupting the physiology and morphology of plants [5].

An experiment was designed and conducted for studying the effects of chromium on five species of plants; the present study is a comparative report of the unfavourable effects of varying concentrations of chromium on seed germination, root and shoot growth and fresh weight of Vigna radiata L, Trigonella foenum-graceum L, Oryza sativa L, Sorghum vulgare L and Pennisetum glaucum L. The aim of our study was to understand and compare the response and sensitivity of these plants to heavy metal stress to illustrate their tolerance potential.

\section{Materials and Methods}

For understanding the effects of chromium on germination plants of Vigna radiata L, Trigonella foenum-graceum L, Oryza sativa L, Sorghum vulgare L and Pennisetum glaucum L. were grown from seeds. The seeds of all the plants were bought from American hybrid Seed Company. The plant species were identified from the Botanical Survey of India.

Ten seeds of uniform colour and size were placed on a doublelayered filter paper in each of the petri dishes having a diameter of 9 centimeters. Preceding the placement in petri dishes, the seeds were sterilized using bavistin solution prepared by dissolving $200 \mathrm{mg}$ of bavistin powder in $100 \mathrm{ml}$ distilled water. The seeds were kept in this solution for 5 minutes followed by a through rinse using distilled water.

The filter paper was moistened with varying concentrations (1, $3,5,10,50,100,200,300,500 \mathrm{ppm}$ ) of heavy metal solutions, over a period of 7 days. For the treatment $5 \mathrm{~mL}$ of solution was added on the first day followed by $2 \mathrm{ml}$ on alternate days or depending on the level of moisture every day. Triplicates of each treatment were studied in completely randomized design along with a separate set of control using distilled water.

A stock solution of chromium (1000 ppm) was prepared using Potassium dichromate $\left(\mathrm{K}_{2} \mathrm{Cr}_{2} \mathrm{O}_{7}\right)$ of analytical grade obtained 
from Loba Chemie. Accurately weighed $2.828 \mathrm{~g}$ of $99.9 \%$ analytical grade $\mathrm{K}_{2} \mathrm{Cr}_{2} \mathrm{O}_{7}$ in $1000 \mathrm{~mL}$ of distilled water to obtain $1000 \mathrm{ppm}$ of $\mathrm{Cr}$ stock solution. In order to obtain desired concentrations of $1,3,5,10,50,100,200,300,500$ ppm for the treatment of seeds of selected crops, the stock solution was further diluted.

Germination was observed after 24 hours and for further 7 days to record a constant percentage of germination. Total germination (GT) and Seedling vigour index (SVI) [6], length of the radicle $(\mathrm{cm})$, length of the plumule $(\mathrm{cm})$ and fresh weight $(\mathrm{g})$ were parameters selected and recorded for this study. Total germination (GT) which is a measure of the time for a population of seeds to germinate in order to estimate its viability and is expressed as a percentage and it was calculated using the formula GT=no. of seeds germinated/total seeds $x$ 100. Length of the radicle $(\mathrm{cm})$ and length of the plumule $(\mathrm{cm})$ of the seedlings were noted after a period of 7 days using a standard centimetre scale. Fresh weight $(\mathrm{g})$ of each individual seedling was recorded using a digital balance.

Seed vigour index (SVI) vigour helps understand the potential for emergence and development of seedlings in field conditions. SVI is considered to be a sensitive and important component of germination studies as it provides a better understanding of seed damage and deterioration and response to stressors.

Seedling vigour index was calculated by following formula:

$\mathrm{SVI}=$ Germination $\% \times$ Seedling length $(\mathrm{cm})$

Table 1. Effect of chromium on total germination (\%).

\begin{tabular}{|c|c|c|c|c|c|}
\hline Concentration in ppm & Vigna radiata $L$ & Trigonella foenum-graceum $L$ & Pennisetum glaucum $L$ & $\begin{array}{l}\text { Sorghum vulgare } \\
L\end{array}$ & Oryza sativa $L$ \\
\hline Control & 100 & 100 & 100 & 100 & 100 \\
\hline 1 & 100 & 95 & 65 & 100 & 95 \\
\hline 3 & 100 & 90 & 65 & 95 & 100 \\
\hline 5 & 100 & 100 & 95 & 90 & 100 \\
\hline 10 & 100 & 95 & 95 & 85 & 95 \\
\hline 50 & 100 & 70 & 95 & 70 & 95 \\
\hline 100 & 100 & 100 & 90 & 90 & 55 \\
\hline 200 & 55 & 40 & 50 & 55 & 10 \\
\hline 300 & 70 & 30 & 50 & 60 & 0 \\
\hline 500 & 40 & 10 & 40 & 45 & 0 \\
\hline
\end{tabular}

\section{Effect of chromium on length of radicle}

Based on the values recorded in Table 2, detrimental effects were observed from 50 to $500 \mathrm{ppm}$. A slight emergence of radicle was observed above $50 \mathrm{ppm}$ for plant studied except Vigna radiata $\mathrm{L}$, with a recorded length of $(1.99 \pm 0.98) \mathrm{cm}$ at 300 ppm. Heavy metal treatment from 50 ppm onwards drastically decreased the radicle emergence in all the plants. Trigonella foenum-graceum L and Oryza sativa L showed no radicle
Seedling length $=\mathrm{RL}+\mathrm{SL}$ where $\mathrm{RL}$ is root length $(\mathrm{cm}), \mathrm{SL}$ is shoot length.

Statistical analysis of the data was done using SPSS software ver. 11.0. The data was processed using excel 2013 for paired t-test to establish the level of significance at 0.01 and 0.05 .

\section{Results and Discussion}

\section{Effect of chromium on total germination}

As per the data in Table 1 higher concentrations of chromium severely affected the germination of selected plants, as compared to control. Amongst the five species, the germination percentage of Trigonella foenum-graceum $\mathrm{L}$ was recorded to be the lowest whereas, Vigna radiata L showed higher tolerance to chromium treatment in comparison to others. The effects on germination of Pennisetum glaucum L and Sorghum vulgare $\mathrm{L}$ are fairly comparable across all the concentrations, with a significant drop in the germination percentage from 200 ppm onwards. Oryza sativa L fared poorly with increasing concentrations of chromium, with no germination recorded at 300 and $500 \mathrm{ppm}$. The reduced germination of seeds under $\mathrm{Cr}$ stress would be due to the depressive effect of $\mathrm{Cr}$ on the subsequent transport of sugars to the embryo axis. Protease activity increases simultaneously with the chromium treatment which could also contribute to the reduction in germination of chromium treated seeds [7]. emergence above $200 \mathrm{ppm}$. Similar values were recorded in Pennisetum glaucum L. $(0.41 \pm 0.26) \mathrm{cm}$ and Sorghum vulgare $\mathrm{L}(0.42 \pm 0.36) \mathrm{cm}$ at $50 \mathrm{ppm}$. In plants, roots are the first organs to come into contact with toxic elements and they usually accumulate more metals than shoots [8-10] thus inhibiting the growth and roots. Roots accumulate higher amount of chromium than the shoot. It could be due to immobilization of chromium in the vacuoles of the root cells, thus rendering it less toxic, which may be a natural toxicity 
response of the plant [11]. Based on the work of several researchers, major morphological effects of heavy metals on roots can be decrease in root elongation, root hair collapse, and decrease in the number of roots [12-14].

Table 2. Effect of chromium on length of radicle (cm).

\begin{tabular}{|c|c|c|c|c|c|}
\hline Concentration in ppm & Vigna radiata $L$. & Trigonella foenum-graceum $L$. & Pennisetum glaucum $L$. & Sorghum vulgare $L$. & Oryza sativa $L$. \\
\hline Control & $11.54 \pm 1.88$ & $3.9 \pm 0.90$ & $7.63 \pm 3.10$ & $8.21 \pm 1.96$ & $5.75 \pm 0.97$ \\
\hline 1 & $10.75 \pm 1.89^{\#}$ & $2.85 \pm 1.54^{*}$ & $6.13 \pm 4.44^{\mathrm{ns}}$ & $7.92 \pm 1.63^{n s}$ & $4.85 \pm 1.25^{\circ}$ \\
\hline 3 & $11.43 \pm 2.88^{\text {ns }}$ & $3.64 \pm 1.31^{\mathrm{ns}}$ & $9.89 \pm 2.75^{\circ}$ & $3.44 \pm 1.77^{*}$ & $2.58 \pm 0.67^{*}$ \\
\hline 5 & $11.18 \pm 2.07^{\mathrm{ns}}$ & $2.16 \pm 0.92^{*}$ & $7.12 \pm 3.84^{\mathrm{ns}}$ & $4.82 \pm 1.75^{\star}$ & $1.70 \pm 0.69^{*}$ \\
\hline 10 & $9.86 \pm 1.40^{*}$ & $2.19 \pm .092^{*}$ & $3.30 \pm 1.66^{*}$ & $3.04 \pm 0.66^{*}$ & $1.01 \pm 0.42^{*}$ \\
\hline 50 & $6.59 \pm 2.54^{*}$ & $1.28 \pm 0.65^{*}$ & $0.41 \pm 0.26^{*}$ & $0.42 \pm 0.36^{*}$ & $0.34 \pm 0.18^{*}$ \\
\hline 100 & $5.44 \pm 1.89^{*}$ & $0.89 \pm 0.38^{*}$ & $0.32 \pm 0.32^{*}$ & $0.16 \pm 0.05^{*}$ & $0.17 \pm 0.11^{*}$ \\
\hline 200 & $2.07 \pm 1.30^{*}$ & $0.5 \pm 0.16^{*}$ & $0.17 \pm 0.18^{*}$ & $0.14 \pm 0.15^{\star}$ & $0.2 \pm 0.00^{*}$ \\
\hline 300 & $1.99 \pm 0.98^{*}$ & $00 \pm 00$ & $0.14 \pm 0.60^{*}$ & $0.11 \pm 0.03^{*}$ & $00 \pm 00$ \\
\hline 500 & $0.08 \pm 0.70^{*}$ & $00 \pm 00$ & $0.13 \pm 0.05^{*}$ & $0.1 \pm 0.5^{*}$ & $00 \pm 00$ \\
\hline
\end{tabular}

${ }^{*} \mathrm{p}<.01{ }^{*} \mathrm{p}<.10^{\mathrm{ns}}$-not significant ${ }^{\circ} \mathrm{p}<.05$

\section{Effect of chromium on length of plumule}

Shoot length gradually decreased with the increase in chromium concentrations (Table 3). The highest length was observed in control Vigna radiata L seedlings (12.04 \pm 1.36$)$ $\mathrm{cm}$. More pronounced effect on seedling growth was observed above 50 ppm chromium concentrations.
Shoot length due to heavy metal stress decreased in order; Trigonella foenum-graceum $\mathrm{L}>$ Oryza sativa $\mathrm{L}>$ Pennisetum glaucum $\mathrm{L}>$ Sorghum vulgare $\mathrm{L}>$ Vigna radiata $\mathrm{L}$. Decrease in shoot length is obvious since destruction of root cells by $\mathrm{Cr}$ may cause decrease in nutrient and water mobility from root to shoot [15].

Table 3. Effect of chromium on length of plumule $(\mathrm{cm})$.

${ }^{*} \mathrm{p}<.01 \mathrm{\# p}<.10$ ns-not significant ${ }^{\circ} \mathrm{p}<.05$

\begin{tabular}{|c|c|c|c|c|c|}
\hline Concentration in ppm & Vigna radiata $\mathrm{L}$ & Trigonella foenum-graceum $\mathrm{L}$ & Pennisetum glaucum $\mathrm{L}$ & Sorghum vulgare $\mathrm{L}$ & Oryza sativa $\mathrm{L}$ \\
\hline Control & $12.04 \pm 1.36$ & $6.69 \pm 0.72$ & $5.95 \pm 1.10$ & $6.74 \pm 2.51$ & $4.77 \pm 0.40$ \\
\hline 1 & $5.15 \pm 1.52^{*}$ & $5.46 \pm 1.16^{*}$ & $3.98 \pm 1.74^{*}$ & $7.78 \pm 1.00^{\circ}$ & $4.6 \pm 0.54^{\mathrm{ns}}$ \\
\hline 3 & $5.65 \pm 1.55^{*}$ & $6.84 \pm 2.03^{n s}$ & $5.13 \pm 1.29^{\circ}$ & $4.95 \pm 1.75^{*}$ & $4.02 \pm 0.59^{*}$ \\
\hline 5 & $4.67 \pm 1.80^{*}$ & $5.37 \pm 1.34^{*}$ & $4.58 \pm 1.29^{*}$ & $6.18 \pm 1.66^{\mathrm{ns}}$ & $3.87 \pm 0.74^{*}$ \\
\hline 10 & $3.65 \pm 1.18^{*}$ & $5.09 \pm 2.08^{*}$ & $4.91 \pm 1.19^{*}$ & $5.265 \pm 0.72^{*}$ & $3.96 \pm 0.96^{*}$ \\
\hline 50 & $3.24 \pm 1.56^{*}$ & $3.915 \pm 1.71^{*}$ & $2.96 \pm 1.67^{*}$ & $3.25 \pm 1.29^{*}$ & $2.13 \pm 0.85^{*}$ \\
\hline 100 & $2.36 \pm 1.17^{*}$ & $1.76 \pm 0.86^{*}$ & $2.4 \pm 1.07^{\star}$ & $2.175 \pm 1.01^{*}$ & $0.79 \pm 0.41^{*}$ \\
\hline 200 & $1.00 \pm 0.79^{*}$ & $00 \pm 00$ & $1.27 \pm 0.72^{*}$ & $1.94 \pm 0.72^{*}$ & $0.32 \pm 0.08^{*}$ \\
\hline 300 & $0.81 \pm 0.86^{*}$ & $00 \pm 00$ & $0.94 \pm 0.40^{*}$ & $1.07 \pm 0.59^{*}$ & $00 \pm 00$ \\
\hline 500 & $1.01 \pm 0.04^{*}$ & $00 \pm 00$ & $0.49 \pm 0.46^{*}$ & $0.565 \pm 0.52^{*}$ & $00 \pm 00$ \\
\hline
\end{tabular}

\section{Effect of chromium on fresh weight}

With a reported decrease in the root growth and shoot growth, subsequently the fresh weight of the plant is bound to decrease. Amongst the monocotyledonous plants minimum seedling weight was recorded in Pennisetum glaucum L at $(0.0199 \pm$ $0.00) \mathrm{g}$ and Oryza sativa L at $(0.0212 \pm 0.001) \mathrm{g}$, whereas in dicotyledonous plants Trigonella foenum-graceum $\mathrm{L}$ showed a low of $(0.0641 \pm 0.002) \mathrm{g}$ (Table 4$)$. This decrease in biomass 
productivity might be attributed to a disruption in nitrogen metabolism of seedlings under chromium stress [16].

Table 4. Effect of chromium on fresh weight ( $g$ ). ${ }^{*} \mathrm{p}<.01 \mathrm{\# p}<.10$ ns-not significant ${ }^{\circ} \mathrm{p}<.05$

\begin{tabular}{|c|c|c|c|c|c|}
\hline Concentration in ppm & Vigna radiata $L$ & Trigonella foenum-graceum $L$ & Pennisetum glaucum $\mathrm{L}$ & Sorghum vulgare $\mathrm{L}$ & Oryza sativa $\mathrm{L}$ \\
\hline Control & $0.2937 \pm 0.05$ & $0.1673 \pm 0.03$ & $0.0663 \pm 0.01$ & $0.1214 \pm 0.01$ & $0.0451 \pm 0.004$ \\
\hline 1 & $0.2379 \pm 0.06^{*}$ & $0.1283 \pm 0.03^{*}$ & $0.0642 \pm 0.02^{\mathrm{ns}}$ & $0.1266 \pm 0.03^{n s}$ & $0.0401 \pm 0.00^{*} 6$ \\
\hline 3 & $0.2195 \pm 0.05^{*}$ & $0.1188 \pm 0.04^{*}$ & $0.0462 \pm 0.01^{*}$ & $0.0941 \pm 0.03^{*}$ & $0.0321^{*} \pm 0.006^{*}$ \\
\hline 5 & $0.2302 \pm 0.06^{*}$ & $0.1206 \pm 0.04^{*}$ & $0.0629 \pm 0.03^{n s}$ & $0.0849 \pm 0.02^{*}$ & $0.0386 \pm 0.005^{*}$ \\
\hline 10 & $0.2091 \pm 0.04^{*}$ & $0.1267 \pm 0.04^{*}$ & $0.0444 \pm 0.01^{*}$ & $0.0791 \pm 0.01^{*}$ & $0.0328 \pm 0.005^{*}$ \\
\hline 50 & $0.2295 \pm 0.06^{*}$ & $0.1255 \pm 0.03^{*}$ & $0.0321 \pm 0.01^{*}$ & $0.0767 \pm 0.02^{*}$ & $0.0293 \pm 0.003^{*}$ \\
\hline 100 & $0.2261 \pm 0.04^{*}$ & $0.1069 \pm 0.02^{*}$ & $0.0296 \pm 0.01^{*}$ & $0.0666 \pm 0.03^{*}$ & $0.0249 \pm 0.002^{*}$ \\
\hline 200 & $0.1599 \pm 0.03^{*}$ & $0.0641 \pm 0.002^{*}$ & $0.0199 \pm 0.00^{*}$ & $0.0447 \pm 0.00^{*}$ & $0.0212 \pm 0.001^{*}$ \\
\hline 300 & $0.1406 \pm 0.04^{*}$ & $00 \pm 00$ & $0.0178 \pm 0.00^{*}$ & $0.0465 \pm 0.00^{*}$ & $00 \pm 00$ \\
\hline 500 & $0.1260 \pm 0.04^{*}$ & $00 \pm 00$ & $0.0141 \pm 0.00^{*}$ & $0.0372 \pm 0.01^{*}$ & $00 \pm 00$ \\
\hline
\end{tabular}

\section{Effect of chromium on seed vigour index}

The decrease in the total germination percentage, length of radicle and plumule has a negative influence on seed vigour of all species. A decline in the average SVI was observed from the highest recorded value of 1587 in Vigna radiata $\mathrm{L}$ at $1 \mathrm{ppm}$ to 72.60 at $500 \mathrm{ppm}$ (Table 5). In Trigonella foenumgraceum $\mathrm{L}$ the overall health was significantly affected based on the drop in seed vigour index from 789.92 to 2.50 .
Increasing concentration of chromium decreased seed vigour compared to the control samples, for Pennisetum glaucum L, Sorghum vulgare L. ranging from 1570 to 29.92. As no germination was recorded in Oryza sativa L. at 300 and 500 ppm the SVI calculated is zero. The findings of this study were in agreement with other researchers who reported increasing metal concentrations decreased rapeseed seedling vigour indexes [17-20].

Table 5. Effect of Chromium on Seed Vigour Index (SVI).

\begin{tabular}{|c|c|c|c|c|c|}
\hline Ppm & Vigna radiata $\mathrm{L}$ & Trigonella foenum-graceum $L$ & Pennisetum glaucum $\mathrm{L}$ & Sorghum vulgare $\mathrm{L}$ & Oryza sativa $\mathrm{L}$ \\
\hline Control & 2358 & 1059 & 1362.5 & 1495.5 & 1034.5 \\
\hline 1 & 1587 & 789.92 & 657.47 & 1570 & 898.2 \\
\hline 3 & 1699.5 & 943.2 & 974.35 & 797.05 & 660.5 \\
\hline 5 & 1586 & 753.5 & 1111.97 & 990.45 & 557.5 \\
\hline 10 & 1352 & 692.07 & 780.9 & 705.92 & 472.1 \\
\hline 50 & 984 & 363.65 & 321 & 256.9 & 235.6 \\
\hline 100 & 781 & 265.5 & 244.8 & 210.15 & 52.8 \\
\hline 200 & 168.8 & 23.2 & 72 & 114.67 & 5.2 \\
\hline 300 & 196.7 & 7.5 & 54.25 & 70.8 & 0 \\
\hline 500 & 72.6 & 2.5 & 25.2 & 29.92 & 0 \\
\hline
\end{tabular}

\section{Conclusion}

The results of this study showed that chromium at all concentrations had a negative effect on all the growth parameters in comparison to control. It can be concluded that the level of chromium at and above $200 \mathrm{ppm}$ proved to be lethal to all the crops selected. Based on the comparison of the toxic effect on germination percentage and overall seedling growth, Vigna radiata L, has coped best to heavy metal stress, while Trigonella foenum-graceum L, and Oryza sativa L seedlings were seriously inhibited. The accumulation of chromium in plants depends on its oxidation state, studies have reported, the chromium accumulation was higher when contaminated with $\mathrm{Cr}$ (VI), as compared $\mathrm{Cr}$ (III). It has also been reported that the absorption mechanisms of $\mathrm{Cr}$ (III) and $\mathrm{Cr}(\mathrm{VI})$ are different suggesting that use of metabolic inhibitors 
decreases the uptake of $\mathrm{Cr}(\mathrm{VI})$ but that was not the same for Cr(III).

Since the plants selected in this study were common crops, our results can be considered as indicator of tolerance potential for chromium, in order to devise strategies to overcome stress by understanding the biochemistry of heavy metal toxicity, for their potential to be planted in contaminated sites and lower the risk to man of ingesting a contaminated produce as soil contaminated by chromium is a major concern for sustainable agriculture.

\section{References}

1. Zayed AM, Terry N. Chromium in the environment: factors affecting biological remediation. Plant Soil. 2003;249(1): 139-56.

2. Skeffington RA, Shewry PR, Peterson PJ. Chromium uptake and transport in barley seedlings (Hordeum vulgare L.). Planta. 1976;132(3):209-14.

3. Kim J, Kim JH, Lee CE, et al. Expression of yeast transcriptional activator MSN1 promotes accumulation of chromium and sulfur by enhancing sulfate transporter level in plants. FEBS Letters. 2006;580(1):206-10.

4. Cervantes C, García JC, Devars S, et al. Interactions of chromium with microorganisms and plants, FEMS Microbiol Reviews, 200;25(3):335-47.

5. Simate GS, Ndlovu S. Acid mine drainage: Challenges and opportunities. J Environ Chem Eng. 2014;2:1785-803.

6. Abdul-Baki A, Anderson JD. Vigor determination in Soybean seed by multiple criteria. Crop Sci. 1973;13(6): 630-3.

7. Zeid IM. Responses of Phaseolus vulgaris to chromium and cobalt treatments. Biol Plant. 2001;44(1);111-5.

8. Salt DE, Prince RC, Pickering IJ, et al. Mechanisms of cadmium mobility andaccumulation in Indian mustard. Plant Physiol. 1995;109(4):1427-33.

9. Wójcik M, Tukiendorf A. Cd-tolerance of maize, rye and wheat seedlings. Acta Physiol Plant. 1999;21(2):99-107.

10. Rout GR, Samantaray S, Das P. Differential lead tolerance of rice and black gram genotypesin hydroponic culture. Rost Výroba (Praha) 2001;47:541-8.

11. Shanker AK, Djanaguiraman M, Sudhagar R, et al. Differential antioxidative response of ascorbate glutathione pathway enzymes and metabolites to chromium speciation stress in green gram (Vigna radiata (L.) R. Wilczek, cv. CO 4) roots. Plant Sci. 2004;166(4):1035-43.

12. Barcelo J, Paschenrieder CH, Gunse B. Water relations of chromium treated bushbean plants (Phaseolus vulgaris L. cv. Contender) under both normal and water sterss conditions. J Exp Bot. 1986;37(2):178-87.

13. Punz WF, Sieghardt H. The response of roots of herbaceous plant species to heavy metals. Environ Exp Bot. 1993;33(1):85-98

14. Hagemeyer J, Breckle SW. Growth under trace element stress. In: Waisel Y, Eshel A, Kafkafi U (eds) Plant root: the hidden half, 2nd edn. Dekker, New York, 1996:415-33.

15. Saddiqe Z, Farooq A, Khan F, et al. Effect of Chromium (VI) on physical growth and biochemical parameters of Wheat (Triticum aestivum L.) seedlings. Biologia (Pakistan) 2015;61(2):219-26.

16. Chatterjee J, Chatterjee C. Phytotoxicity of cobalt, chromium and copper in cauliflower. Environ Pollut. 2000;109(1):69-74.

17. Ivanova EM, Kholodova VP, Kuznetsov VIV. Biological effects of high copper and zinc concentrations and their interaction in rapeseed plants. Rus J Plant Physiol. 2010;57(6):806-14.

18. Tomar RS, Jajoo A. Photomodified fluoranthene exerts more harmful effects as compared to intact fluoranthene by inhibiting growth and photosynthetic processes in wheat. Ecotoxicol Environ. 2015;122:31-6.

19. Sharma S, Rana S, Thakkar A, et al. Physical, chemical and phytoremediation technique for removal of heavy metal. J Heavy Metal Toxic Disea. 2016;1(2):3-10.

20. Chinnannan K, Mohammad O, Kumar S, et al. Isolation and characterization of multi-potential Rhizobium strain ND2 and its plant growth-promoting activities under $\mathrm{Cr}$ (VI) stress. Arch Agron Soil Sci. 2017;63(8):1058-69.

\section{*Correspondence to:}

Nitesh Joshi

Associate professor

Department of Botany

Rizvi college of Arts

Science and Commerce

India

E-mail: niteshcjoshi@gmail.com 